\title{
PHYTOCHEMICAL SCREENING, ANTIOXIDANT AND ANTIBACTERIAL ACTIVITIES OF EXTRACTS AND FRACTIONS OF Dillenia suffruticosa LEAVES
}

\author{
FARAZIMAH YAKOP ${ }^{1,3}$, MALAI HANITI SHEIKH ABDUL HAMID ${ }^{1,3 *}$, NORHAYATI AHMAD ${ }^{2,3}$, \\ MOHAMED ABDUL MAJID ${ }^{2,3,4}$, MANOHARAN KARUPPIAH PILLAI ${ }^{3,5}$ and HUSSEIN TAHA ${ }^{2,3}$ \\ ${ }^{1}$ Chemical Sciences, Faculty of Science, Universiti Brunei Darussalam, Jalan Tungku Link, \\ Gadong BE1410, Brunei Darussalam \\ ${ }^{2}$ Environmental and Life Sciences, Faculty of Science, Universiti Brunei Darussalam, \\ Jalan Tungku Link, Gadong BE1410, Brunei Darussalam \\ ${ }^{3}$ Herbal Drug Discovery Laboratory, Faculty of Science, Universiti Brunei Darussalam, \\ Jalan Tungku Link, Gadong BE1410, Brunei Darussalam \\ ${ }^{4}$ Rimba Ilmu, Universiti Malaya, 50603 Kuala Lumpur, Malaysia \\ ${ }^{5}$ Faculty of Science and Technology, Department of Chemistry and Chemical Technology, \\ National University of Lesotho, P.O Roma 180, Kingdom of Lesotho, South Africa \\ *E-mail:haniti.hamid@ubd.edu.bn
}

Accepted 24 May 2020, Published online 30 June 2020

\begin{abstract}
Dillenia suffruticosa or 'Simpur bini' is known to have ethnomedicinal properties and had been used traditionally to heal wounds, relieve fever and rheumatism. There has been limited studies carried out on this species, therefore, this study aims to evaluate the phytochemical contents, antioxidant and antibacterial activities of aqueous extract, methanol extract and its fractions obtained from the leaves of D. suffruticosa. The dried leaves were extracted using methanol before successive solvent partitioning was carried out on the extract using hexane, chloroform, ethyl acetate and diethyl ether. In addition to this, aqueous decoction was conducted. The antioxidant activities were determined using Total Phenolic Content (TPC), Total Flavonoid Content (TFC) and 2,2-diphenyl-1-picryl-hydrazyl-hydrate (DPPH) free radical scavenging methods. Phytochemical screening had shown that most of the extracts and fractions contained alkaloids, steroids, phenolics, flavonoids and saponins. The diethyl ether and ethyl acetate fractions showed higher TPC and TFC values. The diethyl ether and ethyl acetate fractions also showed higher antioxidant activities determined via DPPH assay. Antibacterial activities determined using disc diffusion assay showed the methanol extract and its fractions had antibacterial activity against Staphylococcus aureus, with the diethyl ether fraction having comparable activity with the standard antibiotic streptomycin. However, inhibition against Bacillus subtilis was only observed in hexane, chloroform and diethyl ether fractions. No inhibition was observed against Escherichia coli and Pseudomonas aeruginosa. This study identified the diethyl ethyl and ethyl acetate fractions of $D$. suffruticosa leaves as potential sources of bioactive compounds. Further investigations on the bioassay-guided isolation of bioactive compounds of this species may lead to the discovery of new pharmaceutical or effective antimicrobial agents.
\end{abstract}

Key words: Dillenia suffruticosa, Dilleniaceae, antioxidant activity, antibacterial activity, flavonoids, phenolics, phytochemical screening

\section{INTRODUCTION}

The use of conventional medicine which is primarily based on plants play a vital role in health care applications, whereby about $80 \%$ of the world's population are dependent on it (Tuama \& Mohammed, 2018). Dillenia suffruticosa (Griff)

\footnotetext{
* To whom correspondence should be addressed.
}

Martelli also locally known as 'Simpur bini', is an evergreen shrub which belongs to the Dilleniaceae family found in forests of Brunei Darussalam. The plant grows up to 7 metres high and has large spirally arranged leaves with the size of $37 \times 25 \mathrm{~cm}$. The flowers are scentless (about 10-13 cm wide) with bright yellow petals and white stamens that could bloom in less than a day and the fruits are bright pink with red seeds. 
D. suffruticosa has traditionally been used as a wound healer and to relieve fever (Goh et al., 2017). Moreover, this plant has been used to treat rheumatism (Hanum, 1999) and as an astringent (Wiart et al., 2004). Its twigs and leaf stalks can be broken off and the exudate applied to an external wound, while the young pounded leaves are used as poultice to stop bleeding (Department of Agriculture, 2000). A poultice of the leaves can also be applied to affected areas to relieve from inflammation. D. suffruticosa has also been used in postpartum treatment (Wiart et al., 2004) and their fruits have been used in the treatment of cancerous growth (Graham et al., 2000).

There is limited scientific literature that supports the ethnomedicinal use of D. suffruticosa. To date, only two studies (Wiart et al., 2004; Armania et al., 2013) have reported the bioactivities of this plant, using the methanol and aqueous extracts obtained from various parts of the plant such as roots, leaves, fruits and flowers. It was reported that the methanolic extracts from the roots had the best antioxidant activity compared to the other extracts, with the $\mathrm{IC}_{50}$ value of $31.33 \pm 1.15$ $\mu \mathrm{g} \mathrm{mL} \mathrm{mL}^{-1}$ (Armania et al., 2013). Antimicrobial activity of methanolic extract from leaves of $D$. suffruticosa was also evaluated using the disc diffusion method against Bacillus cereus, $B$. subtilis, Candida albicans and Pseudomonas aeruginosa (Wiart et al., 2004). This indicates that with fractionation and isolation of D. suffruticosa, more potent antioxidant and antibacterial activities can be further analysed.

The aim of the present study was to evaluate the extracts and fractions obtained from the leaves of D. suffruticosa for their phytochemical contents and for their antioxidant and antibacterial activities.

\section{MATERIALS AND METHODS}

\section{Materials}

The fresh leaves of $D$. suffruticosa were collected from Kampung Batu Ampar, Brunei Darussalam, in April 2014. A voucher specimen was deposited in the Universiti Brunei Darussalam Biology Herbarium under the reference number UBDH/FHY01.

All solvents (methanol, hexane, chloroform, ethyl acetate and diethyl ether), nutrient broth and Mueller Hinton agar (MHA) were purchased from Merck, Germany. All other chemicals were purchased from Sigma-Aldrich, Germany. Spectrophotometric measurements were carried out using $2 \mathrm{~mL}$ plastic cuvettes and a single beam UV spectrophotometer (Optizen 1412V, Mecasys, Korea).

\section{Preparation of extracts}

The leaves were air-dried and subsequently powdered using an electric blender. A total of $3 \mathrm{~kg}$ of powdered leaves were extracted with $5 \mathrm{~L}$ methanol using Soxhlet extraction. The resulting solution was filtered using Whatman No. 2 filter paper and concentrated under vacuum and $654 \mathrm{~g}$ of methanolic crude extract was obtained. For further analysis, $50 \mathrm{~g}$ of this extract was stored at $4^{\circ} \mathrm{C}$ but the remainder was dissolved in $1 \mathrm{~L}$ of methanol and $100 \mathrm{~mL}$ of distilled water, followed by successive fractionation with $1 \mathrm{~L}$ of hexane, $1 \mathrm{~L}$ of chloroform and $1 \mathrm{~L}$ of ethyl acetate (Lakache et al., 2016). After this successive fractionation, it was found that a small amount of orange-yellow precipitate was present in the remaining methanol-aqueous mixture and was found to be soluble in diethyl ether. Thus, a final step of fractionation was carried out using a total of $500 \mathrm{ml}$ diethyl ether. All solvents were removed under vacuum using an IKA rotary evaporator to dryness, and the resulting solid residues were stored at $4^{\circ} \mathrm{C}$ until further use.

The aqueous extract was obtained by replicating the traditional methods used by the locals to prepare the D. suffruticosa decoction, which was by heating $5 \mathrm{~g}$ of the leaves in distilled water at $80^{\circ} \mathrm{C}$ for an hour. It was concentrated under vacuum and lyophilised using a freeze-drier overnight. The resulting powder was stored in a desiccator until further use. The systematic diagram of the preparation of the extracts is shown in Figure 1.

\section{Phytochemical screening}

The extracts and fractions were each analysed for the presence of alkaloids, steroids, phenolics, flavonoids and saponins according to the methods previously described (Edeoga et al., 2005; Ayoola et al., 2008; Lakache et al., 2016).

\section{Alkaloids}

$0.2 \mathrm{~g}$ of the extract or fraction was treated with warm $2 \%$ sulphuric acid $(5 \mathrm{~mL})$ and filtered. A few drops of Dragendorff's reagent was added to the filtrate. Orange-red precipitate indicates the presence of alkaloids.

\section{Steroids}

$0.5 \mathrm{~g}$ of the extract or fraction was treated with chloroform $(5 \mathrm{~mL})$ and filtered. A few drops of concentrated sulphuric acid were carefully added into the filtrate, shaken and allowed to stand. The formation of red or yellow precipitate indicates the presence of steroids. 


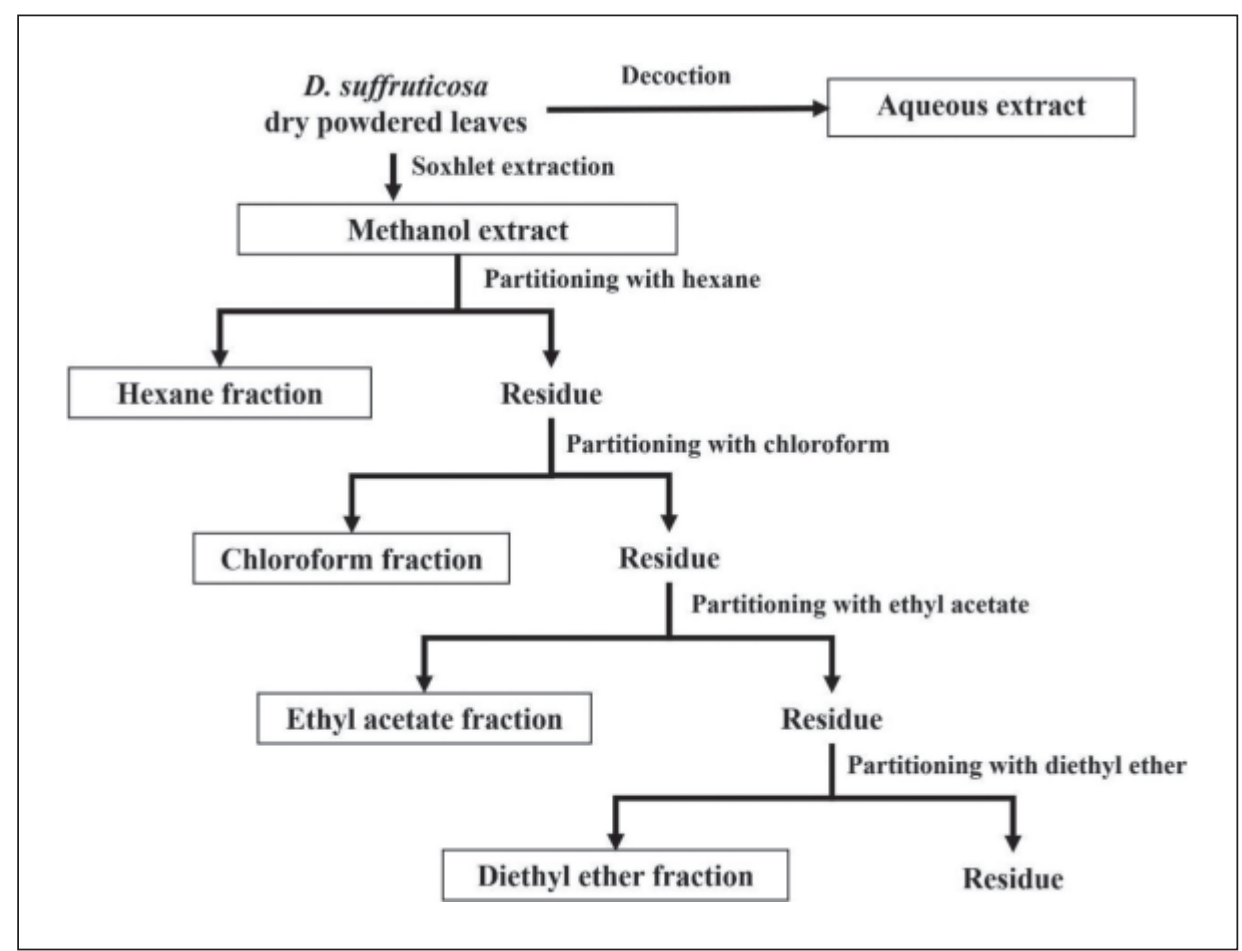

Fig. 1. The systematic diagram of the preparation of extracts.

\section{Phenolic compounds}

3 to 5 drops of $10 \%$ aqueous iron (III) chloride were added to $1 \mathrm{~mL}$ of the extract or fraction. The presence of phenolic compounds was detected by a change in colour from the initial bright yellow solution to form a dark green solution.

\section{Flavonoids}

$5 \mathrm{~mL}$ of $10 \%$ sodium hydroxide was added to $2 \mathrm{~mL}$ of the extract or fraction. The formation of an intense yellow solution, which decolourised upon the addition of a few drops of dilute acid, indicates the presence of flavonoids.

\section{Saponins}

The extract or fraction (1 g) was diluted with distilled water in a $15 \mathrm{~mL}$ centrifuge tube and shaken vigorously. The formation of $1 \mathrm{~cm}$ layer of foam that persists for 15 minutes indicates the presence of saponins.

\section{Antioxidant activities}

\section{Total phenolic content (TPC)}

The TPC was estimated using the FolinCiocalteu's assay (Ebrahimzadeh et al., 2008). To each of the $0.5 \mathrm{~mL}$ aliquots of various concentrations of gallic acid $(1,5,10,25,50,100,250$ and 500 $\mathrm{mg} \mathrm{mL} \mathrm{L}^{-1}$, dissolved in methanol) or $1000 \mu \mathrm{g} \mathrm{mL}-1$ of the extract or fraction dissolved in methanol, 5 $\mathrm{mL}$ of 10 -fold diluted Folin-Ciocalteu solution and $4 \mathrm{~mL}$ of $1 \mathrm{~mol} \mathrm{~L}^{-1}$ sodium carbonate were added and incubated in the dark for 30 minutes before the absorbance was measured at $765 \mathrm{~nm}$. Each sample was analysed in triplicate, with methanol as the blank. A standard curve of gallic acid was plotted and linear regression was used to estimate the gallic acid equivalence (GAE) of each extract/fraction, which was expressed as mg gallic acid per g dry weight of extract or fraction (mgGAE/gDW).

\section{Total flavonoid content (TFC)}

The TFC was analysed using aluminium chloride method (Ebrahimzadeh et al., 2008). To each of the $0.5 \mathrm{~mL}$ aliquots of various concentrations of quercetin $(10,25,50,100,150,200$ and $250 \mathrm{mg}$ $\mathrm{mL}^{-1}$, dissolved in methanol) or $1000 \mu \mathrm{g} \mathrm{mL}^{-1}$ of the extract or fraction, dissolved in methanol, $100 \mu \mathrm{L}$ each of $10 \%$ aluminium chloride and $10 \%$ potassium acetate, $1.5 \mathrm{~mL}$ methanol and $2.8 \mathrm{~mL}$ distilled water were added. The absorbance was measured at 415 $\mathrm{nm}$ after a 30-minute incubation. Each sample was analysed in triplicate, with methanol as the blank. A standard curve of quercetin was plotted and linear regression was used to estimate the quercetin equivalence (QE) of each extract/fraction, which was expressed as mg quercetin per g dry weight of extract or fraction (mgQE/gDW).

\section{DPPH radical scavenging activity}

The DPPH radical scavenging activity of extract or fraction was evaluated following the procedure given in the literature (Vélez-González et al., 2008) with slight modification. To each of 
the $200 \mu \mathrm{L}$ aliquots of the reference standards (Quercetin or Trolox; 1, 5, 10, 25 and $50 \mu \mathrm{gL}^{-1}$, dissolved in methanol) or extracts/fractions $(1,10$, $25,50,100,250,500,750$ and $1000 \mu \mathrm{g} \mathrm{mL}^{-1}$, unless otherwise stated), $1 \mathrm{~mL}$ of the $50 \mu \mathrm{g} \mathrm{mL}^{-1}$ methanolic DPPH solution was added and incubated in the dark for 30 minutes. For control, $200 \mu \mathrm{L}$ of $100 \%$ methanol was used instead. Absorbance was measured at $517 \mathrm{~nm}$ with methanol as the blank. All samples were measured in triplicate. The hexane fraction did not show any inhibition within the range of 1 to $750 \mu \mathrm{g} \mathrm{mL}^{-1}$, therefore the assay was further carried out at higher concentrations of 1000 , 1500,2000 and $2500 \mu \mathrm{g} \mathrm{mL}^{-1}$.

The percentage DPPH radical scavenging activity was calculated using the following formula: $\left[\left(\mathrm{Abs}_{\text {control }}-\mathrm{Abs}_{\text {sample }}\right) /\left(\mathrm{Abs}_{\text {control }}\right)\right] \times 100 \%$, where $\mathrm{Abs}_{\text {control }}$ is the measured absorbance with the methanol control, while $\mathrm{Abs}_{\text {sample }}$ is the measured absorbance with the reference standards or extracts. To calculate $\mathrm{IC}_{50}$, which is the concentration of extract that showed $50 \%$ inhibition, radical scavenging activity against concentration was plotted and the concentration was estimated via linear regression.

\section{Antibacterial analysis}

The antibacterial activities of each extract were evaluated against four bacterial strains i.e. Bacillus subtilis [American Type Culture Collection (ATCC) cat. no. 6633], Staphylococcus aureus (ATCC 25923), Escherichia coli (ATCC 25922) and Pseudomonas aeruginosa (ATCC 27853). Disc diffusion assay was used as previously described (Kuete et al., 2008; Zhang et al., 2012; Snoussi et $a l ., 2016)$. All bacterial strains were grown in nutrient broth for 24 hours at $37^{\circ} \mathrm{C}$ before they were adjusted to 0.5 McFarland standard and inoculated onto MHA plates. A $10 \mu \mathrm{L}$ aliquot of extract/fraction $\left(100,300\right.$ and $500 \mathrm{mg} \mathrm{mL}^{-1}$ in methanol) was impregnated onto a sterile $6 \mathrm{~mm}$ filter paper disc and then placed onto the plates. A disc with 100\% methanol was used as the negative control, while a disc with $0.5 \mu \mathrm{L}$ of $20 \mathrm{mg} \mathrm{mL}^{-1}$ streptomycin (antibiotic) as the reference standard. The plates were then incubated at $37^{\circ} \mathrm{C}$ overnight before the measurement of inhibition zone was carried out. The test was done in triplicate for each extract against each microorganism. The aqueous extract was not tested due to insufficient yield obtained from extraction.

\section{Statistical analysis}

Statistical analysis was conducted by using oneway ANOVA with posthoc Tukey HSD test, where $p$ value $<0.05$ was considered as significant.

\section{RESULTS AND DISCUSSION}

\section{Extracts/Fractions}

In total, there were two crude extracts and four partition fractions obtained in this study and the percentage yields are shown in Table 1 . Soxhlet extraction with methanol produced higher yield compared to aqueous extraction, whereas partitioning with chloroform produced higher yield compared to the other solvents. This is due to their different solubility properties in the different solvents (Truong et al., 2019).

\section{Phytochemical screening}

From Table 2, it was found that all of the extracts/fractions contained all of the five tested phytochemicals except for the hexane and diethyl ether fractions. Flavonoids and saponins were not

Table 1. The appearances and yields of $D$. suffruticosa leaves extracts

\begin{tabular}{lcc}
\hline Extract/Fraction & Appearance & Yield (\%) \\
\hline Crude & & \\
Methanol & Brown-green powder & 21.8 \\
Aqueous & Brown powder & 9.2 \\
Partition & & \\
Hexane & Green semi-solid & 5.6 \\
Chloroform & Green powder & 13.4 \\
Ethyl acetate & Deep brown powder & 5.1 \\
Diethyl ether & Red-orange powder & 1.7 \\
\hline
\end{tabular}

Table 2. The phytochemical screening of $D$. suffruticosa leaves extracts/fractions

\begin{tabular}{lccccc}
\hline Extracts/Fractions & Alkaloids & Steroids & Phenolics & Flavonoids & Saponins \\
\hline Methanol & ++ & +++ & ++ & + & ++ \\
Aqueous & + & + & + & + & + \\
Hexane & + & ++ & ++ & + & - \\
Chloroform & ++ & ++ & +++ & ++ & ++ \\
Ethyl acetate & + & ++ & +++ & ++ \\
Diethyl ether & ++ & ++ & + \\
\hline
\end{tabular}

+++: indicates strong positive test; ++: low positive test; +: weak positive test; -: negative test. 
found in the hexane fraction while the diethyl ether fraction did not show the presence of saponins. Flavonoids and saponins are polar compounds, hence they would not dissolve in hexane, which is a non polar solvent. As for the absence of saponins in diethyl ether, this could be explained by the fact that partitioning with this solvent was done last. All the saponins had been extracted into the more polar chloroform and ethyl acetate prior to diethyl ether extraction. Compared with the others, both the ethyl acetate and diethyl ether fractions showed better indication in the presence of phenolics and flavonoids that are known to contribute in antioxidant activities.

The phytochemical screening of D. suffruticosa leaves extracts have not been previously reported. However, a previous study was carried out on the methanol extract of D. suffruticosa roots, which reported the presence of alkaloids, steroids, phenolics, flavonoids and saponins (Armania et al., 2013). Although leaves were not used in this previous study, it is known that some compounds that are present in the roots could also be present in the leaves of the same plants but may be at different concentrations due to the polarity of methanol, where it has the ability to extract these phytochemicals either from leaves or roots (Karimi et al., 2011; Senguttuvan et al., 2014).

\section{Antioxidant activities}

\section{Total phenolic and flavonoid content}

The total phenolic content (TPC) of the extracts/fractions of $D$. suffruticosa leaves are shown in Table 3, calculated using the gallic acid standard curve $\left(\mathrm{y}=0.004 \mathrm{x}+0.140, \mathrm{R}^{2}=0.997\right.$; data not shown). The methanol extract had a higher TPC of $309.91 \pm 3.42 \mathrm{mgGAE} / \mathrm{gDW}$ compared to the aqueous extract $(17.86 \pm 2.71) \mathrm{mgGAE} / \mathrm{gDW}$, whereas for the fractions, the diethyl ether fraction showed the highest TPC of $757.17 \pm 9.67 \mathrm{mgGAE} /$ gDW, followed by the ethyl acetate fraction $(502.75$ $\pm 14.74) \mathrm{mgGAE} / \mathrm{gDW}$ and then by the chloroform fraction $(64.92 \pm 1.80) \mathrm{mgGAE} / \mathrm{gDW}$, while the hexane fraction showed the lowest content among them $(4.03 \pm 1.55) \mathrm{mgGAE} / \mathrm{gDW}$. Statistical analysis showed significant differences between all of them $(p<0.05)$ except for the hexane fraction and aqueous extract, whereby these two were not significantly different from each other $(p=0.279)$.

The total flavonoid content (TFC) were also shown in Table 3, calculated from the quercetin standard curve $\left(\mathrm{y}=0.004 \mathrm{x}+0.015, \mathrm{R}^{2}=0.996\right.$; data not shown). As observed with the TPCs, the TFCs of both the ethyl acetate $(89.69 \pm 7.92 \mathrm{mgQE} / \mathrm{gDW})$ and diethyl ether $(100.38 \pm 7.73 \mathrm{mgQE} / \mathrm{gDW})$ fractions were higher compared to the others. Statistical analysis showed significant differences $(p<0.05)$ between all of them, excluding between the methanol extract and hexane fraction $(p>0.05)$. This could suggest that the concentrations of flavonoids between the methanol and hexane partition extracts were similar but this did not necessarily mean that they were of the same type, as there are different varieties of flavonoids known to exist in plants.

Methanol solvent has been reported to be a better medium for extraction of polyphenols (Boeing et al., 2014; Asghar et al., 2016;). This was observed in the methanol extract with a TPC of $309.91 \pm 3.42 \mathrm{mgGAE} / \mathrm{gDW}$ but the opposite was observed in the TFC of $36.24 \pm 1.36 \mathrm{mgQE} / \mathrm{gDW}$, whereby the aqueous extract showed a significantly higher TFC of $54.63 \pm 3.13 \mathrm{mgQE} / \mathrm{gDW}$ than the methanol extract. This could be caused by the presence of other compounds that behave like flavonoids, such as amino acids, that may contribute to the TFC assay (Kolar et al., 2011).

When comparing the first three consecutive fractions in Table 3, both the TPC and TFC increased with the increase in the solvent polarity of the partitioning solvent, with hexane being the less polar, followed by chloroform and ethyl acetate being the most polar. This observation was consistent with previous studies, whereby an increase in the solvent polarity increases the extraction of

Table 3. TPC, TFC and DPPH radical scavenging activities of $D$. suffruticosa leaf extracts/fractions and reference standards

\begin{tabular}{lccc}
\hline & $\begin{array}{c}\text { Total phenolic content } \\
\text { GAE }(\mathrm{mgGAE} / \mathrm{gDW})\end{array}$ & $\begin{array}{c}\text { Total flavonoid content } \\
\text { QE }(\mathrm{mgQE} / \mathrm{gDW})\end{array}$ & $\begin{array}{c}\text { DPPH radical scavenging } \\
\mathrm{IC}_{50} / \mu \mathrm{m} \mathrm{mL}\end{array}$ \\
\hline Methanol & $309.91 \pm 3.42$ & $36.24 \pm 1.36$ & $305.09 \pm 4.53$ \\
Aqueous & $17.86 \pm 2.71$ & $54.63 \pm 3.13$ & $1168.51 \pm 10.18$ \\
Hexane & $4.03 \pm 1.55$ & $38.77 \pm 1.64$ & $2923.47 \pm 114.10$ \\
Chloroform & $64.92 \pm 1.80$ & $62.42 \pm 2.61$ & $572.00 \pm 10.24$ \\
Ethyl acetate & $502.75 \pm 14.74$ & $89.69 \pm 7.92$ & $29.42 \pm 0.49$ \\
Diethyl ether & $757.17 \pm 9.67$ & $100.38 \pm 7.73$ & $84.60 \pm 2.74$ \\
Quercetin & - & - & $16.36 \pm 0.66$ \\
Trolox & - & - & $38.04 \pm 0.53$ \\
\hline
\end{tabular}

Values shown are average \pm SD of triplicate; GAE: gallic acid equivalence; QE: quercetin equivalence; DW: dry weight of extract/fraction. 
active polar compounds (Goze et al., 2009; Vats, 2012; Addai et al., 2013; Belyagoubi et al., 2016). However, as seen in Table 3 , the diethyl ether fraction interestingly showed the highest TPC of $757.17 \pm 9.67 \mathrm{mgGAE} / \mathrm{gDW}$ and TFC of $100.38 \pm$ $7.73 \mathrm{mgQE} / \mathrm{gDW}$ compared to the other fractions, despite being less polar than chloroform and ethyl acetate. It should be noted that the fractionation with diethyl ether was the last step of the solventsolvent partitioning, after the formation of yellow precipitate was observed, as described in the methodology. The compounds of this precipitate could have slowly accumulated as other compounds were extracted consecutively with hexane, chloroform and ethyl acetate, and consequently they became increasingly insoluble and eventually precipitated (Kebbab-Massime et al., 2017). Hence, it is possible that a less polar solvent could extract more polyphenols than the more polar ones via precipitation.

\section{DPPH radical scavenging activity}

The DPPH radical scavenging activities, expressed as $\mathrm{IC}_{50}$, of the extracts/fractions and two reference standards, quercetin and Trolox, are also shown in Table 3 . The $\mathrm{IC}_{50}$ values were significantly different from each other $(p<0.05)$ except for the ethyl acetate and diethyl ether fractions. When compared to the standards, it was observed that ethyl acetate fraction showed an $\mathrm{IC}_{50}$ activity of $29.42 \pm 0.49 \mu \mathrm{g} \mathrm{mL}^{-1}$ that was comparable to Quercetin $\left(16.36 \pm 0.66 \mu \mathrm{g} \mathrm{mL}^{-1}\right)$ and Trolox (38.04 $\left.\pm 0.53 \mu \mathrm{g} \mathrm{mL}^{-1}\right)$. In addition, this is consistent with the findings from Armania et al. (2013) where an $\mathrm{IC}_{50}$ value of $31.33 \pm 1.15 \mu \mathrm{g} \mathrm{mL}^{-1}$ was obtained for the methanolic extracts from the roots of $D$. suffruticosa. It is known that some compounds that are present in the roots could also be present in the leaves of the same plants as mentioned earlier (Karimi et al., 2011; Senguttuvan et al., 2014). Therefore, the ethyl acetate fraction showed the strongest radical scavenging activity. This is as expected when taking into account of its high TPC and TFC values. In contrast, the hexane fraction showed the least radical scavenging activity with $\mathrm{IC}_{50}$ value of $2923.47 \pm 114.10 \mu \mathrm{g} \mathrm{mL}^{-1}$ and the low TPC of $4.03 \pm 1.55 \mathrm{mgGAE} / \mathrm{gDW}$ and TFC of $38.77 \pm 1.64 \mathrm{mgQE} / \mathrm{gDW}$ observed in this extract could explain this low activity.

It was also observed that the DPPH radical scavenging activity also increased with the increase in the polarity of the extracting solvent, as observed in the TPC and TFC assays. Moreover, the methanol extract $\left(305.09 \pm 4.53 \mu \mathrm{g} \mathrm{mL}^{-1}\right)$ also exhibited a stronger antioxidant activity compared to the aqueous extract $\left(1168.51 \pm 10.18 \mu \mathrm{g} \mathrm{mL}^{-1}\right)$. This could be because, as reported in a previous study (Sulaiman et al., 2011), water has low efficiency in extracting antioxidant compounds from natural products, and it was shown that most of the tested aqueous plant extracts were least effective in scavenging the DPPH radicals compared to the organic-aqueous extracts.

There is only one previous study on the antioxidant activities of the crude methanol extract of D. suffruticosa leaves, which was obtained by maceration of the powdered leaves for 72 hours (Armania et al., 2013), however, in our study, the crude methanol extract was obtained by Soxhlet extraction. The TPC of $309.91 \pm 3.42 \mathrm{mgGAE} / \mathrm{gDW}$ observed in our study is different from the TPC of $236.49 \pm 2.37 \mathrm{mgGAE} / \mathrm{gDW}$ reported previously (Armania et al., 2013) suggests that Soxhlet extraction is better in extracting phenolic compounds than by maceration. This is supported by a previous study that evaluated these different extraction methods and found that Soxhlet extraction (133.70 mg GAE/ g extract) had extracted more phenolic compounds than by maceration (101.31 mg GAE/ g extract) (Sharma \& Cannoo, 2016).

A previous study on the leaves of $D$. indica, which is a close relative of $D$. suffruticosa, reported that it inhibited the DPPH radicals by $82.32 \%$ using $500 \mu \mathrm{g} \mathrm{mL}^{-1}$ of the extract (Kumar et al., 2011). At this same concentration, the crude methanol extract of D. suffruticosa in this present study similarly inhibited the DPPH radicals by $79.93 \%$. Despite being two different species, similar DPPH radical scavenging activities were observed. Hence, although $D$. indica is more frequently studied for its medicinal purposes, D. suffruticosa also has similar potential as $D$. indica and should not be ignored but warrant further studies. In addition, it was reported in another previous study that the high antioxidant activities seen in the $D$. indica crude extracts could be due to the synergistic activity of all the active components present in the extracts, not just from one particular compound (Rashid et al., 2009).

\section{Antibacterial activities}

Plants have been known to produce various chemical components that have different biological activities against various microorganisms (Matic et al., 2016). For the current study, the antibacterial activity was detected when a clear or semi-clear inhibition around the disc containing the extract was present (Alam et al., 2011). The zones of inhibition for the D. suffruticosa extracts, as well as for the reference standard, against four bacterial species, are shown in Table 4 . The negative control $(100 \%$ methanol) did not show any zone of inhibition to any of the bacterial species, as expected. Generally, the results showed that under the conditions tested, no detectable antibacterial activity was observed against the Gram-negative bacteria, E. coli and $P$. 
Table 4. Zone of inhibition of $D$. suffruticosa methanol extract and its fractions

\begin{tabular}{|c|c|c|c|c|c|}
\hline \multirow{2}{*}{ Extract } & \multirow{2}{*}{ Microorganism } & \multicolumn{4}{|c|}{ Zone of inhibition (mm) } \\
\hline & & Streptomycin & $100 \mathrm{mg} \mathrm{mL}^{-1}$ & $300 \mathrm{mg} \mathrm{mL}^{-1}$ & $500 \mathrm{mg} \mathrm{mL}^{-1}$ \\
\hline Methanol & $\begin{array}{l}\text { S. aureus } \\
\text { B. subtilis } \\
\text { E. coli } \\
P . \text { aeruginosa }\end{array}$ & $\begin{array}{c}13.11 \pm 1.76 \\
23.44 \pm 3.4 \\
21.33 \pm 0.71 \\
11.67 \pm 1.15\end{array}$ & $\begin{aligned} 7.17 & \pm 1.22 \\
& - \\
& - \\
& -\end{aligned}$ & $\begin{aligned} 7.44 & \pm 0.98 \\
& - \\
& - \\
& -\end{aligned}$ & $\begin{aligned} 6.89 & \pm 0.78 \\
& - \\
& - \\
& -\end{aligned}$ \\
\hline Hexane & $\begin{array}{l}\text { S. aureus } \\
B . \text { subtilis } \\
\text { E. coli } \\
P . \text { aeruginosa }\end{array}$ & $\begin{array}{c}15.11 \pm 0.601 \\
24.89 \pm 1.45 \\
21.33 \pm 0.58 \\
12.00 \pm 1.00\end{array}$ & $\begin{array}{c}11.67 \pm 2.00 \\
6.33 \pm 0.50 \\
- \\
-\end{array}$ & $\begin{array}{c}10.11 \pm 2.26 \\
6.39 \pm 0.49 \\
- \\
-\end{array}$ & $\begin{aligned} 7.72 & \pm 0.75 \\
6.78 & \pm 0.51 \\
& - \\
& -\end{aligned}$ \\
\hline Chloroform & $\begin{array}{l}\text { S. aureus } \\
\text { B. subtilis } \\
\text { E. coli } \\
\text { P. aeruginosa }\end{array}$ & $\begin{array}{l}14.44 \pm 1.13 \\
23.67 \pm 1.58 \\
21.67 \pm 0.58 \\
12.22 \pm 0.97\end{array}$ & $\begin{aligned} 6.56 & \pm 0.46 \\
6.39 & \pm 0.42 \\
& - \\
& -\end{aligned}$ & $\begin{aligned} 6.83 & \pm 0.56 \\
6.61 & \pm 0.60 \\
& - \\
& -\end{aligned}$ & $\begin{aligned} 6.72 & \pm 0.83 \\
6.94 & \pm 0.81 \\
& - \\
& -\end{aligned}$ \\
\hline Ethyl acetate & $\begin{array}{l}\text { S. aureus } \\
B . \text { subtilis } \\
\text { E. coli } \\
P . \text { aeruginosa }\end{array}$ & $\begin{array}{l}14.89 \pm 0.78 \\
24.78 \pm 2.44 \\
21.00 \pm 1.00 \\
12.33 \pm 1.15\end{array}$ & $\begin{aligned} 6.83 & \pm 0.35 \\
& - \\
& - \\
& -\end{aligned}$ & $\begin{aligned} 8.11 & \pm 0.78 \\
& - \\
& - \\
& -\end{aligned}$ & $\begin{aligned} 8.78 & \pm 0.97 \\
& - \\
& - \\
& -\end{aligned}$ \\
\hline Diethyl ether & $\begin{array}{l}\text { S. aureus } \\
\text { B. subtilis } \\
\text { E. coli } \\
\text { P. aeruginosa }\end{array}$ & $\begin{array}{l}14.33 \pm 0.71 \\
24.89 \pm 1.27 \\
21.33 \pm 0.58 \\
12.67 \pm 0.58\end{array}$ & $\begin{array}{c}10.56 \pm 2.60 \\
- \\
- \\
-\end{array}$ & $\begin{array}{c}12.06 \pm 2.77 \\
6.50 \pm 0.50 \\
- \\
-\end{array}$ & $\begin{array}{c}12.22 \pm 1.66 \\
7.28 \pm 0.97 \\
- \\
-\end{array}$ \\
\hline
\end{tabular}

Values shown are average \pm SD of triplicate; - means no growth inhibition zone.

aeruginosa. However, antibacterial activities were observed against the Gram-positive bacteria, $S$. aureus and B. subtilis.

From Table 4, it is shown that the antibacterial activity of the crude methanol extract was only detected against $S$. aureus but not the other bacteria. In contrast, a previous antimicrobial study on the same plant species (Wiart et al., 2004) showed that a $1 \mathrm{mg}$ methanol extract of $D$. suffruticosa had antibacterial activities against $B$. subtilis, with zone of inhibition of only $7 \mathrm{~mm}$ and $P$. aeruginosa, with inhibition zone of $9 \mathrm{~mm}$. It also had detectable activities against $B$. cereus and Candida albicans. This could perhaps be due to variations in the protocols or strains used. Until now, there is no previous antimicrobial study with regards to the solvent-solvent partition extracts of $D$. suffruticosa. However, there is a previous antimicrobial study of its close relative, $D$. indica, which did solventsolvent partitioning using hexane, carbon tetrachloride, dichloromethane and chloroform. This previous study reported that only the chloroform fraction exhibited antimicrobial activity (Rashid et al., 2009). In contrast, in the present study antibacterial activities were detected in all of the fractions. This might be due to $D$. indica being a different species to that of D. suffruticosa, and therefore would have different phytochemical contents that lead to the results observed here.

Antibacterial activity against $B$. subtilis was only observed with the hexane, chloroform and diethyl ether fractions (Table 4). The results suggest that the hexane and chloroform fractions were more potent than the diethyl ether fraction in inhibiting B. subtilis, as inhibition zone could still be detected at $100 \mathrm{mg} \mathrm{mL}^{-1}$ of either the hexane $(6.33 \pm 0.50 \mathrm{~mm})$ or chloroform fraction $(6.39 \pm 0.42$ $\mathrm{mm})$ but not with the diethyl ether fraction. The methanol extract and its fractions showed antibacterial activity against $S$. aureus (Table 4). However, based on the diameter of the inhibition zone, it seemed that $S$. aureus was mostly affected by the diethyl ether fraction $(10.56 \pm 2.60$ to 12.22 $\pm 1.66 \mathrm{~mm}$ ) compared to the others. Hence, it is possible that the antibacterial compounds in this plant species might have more affinity towards diethyl ether. We observed a slight decrease in the zone of inhibition for both methanol extract and hexane fraction for $S$. aureaus, however, this could be due to solubility decreasing at higher concentrations. The higher TPC and TFC of the diethyl ether fraction might explain the potency of this fraction against $S$. aureus. The polar polyphenolic compounds in the diethyl ether fraction was concentrated and precipitated after the successive partitioning (Kebbab-Massime et al., 2017) despite the solvent being less polar. It has been previously reported that polyphenolic compounds play a substantial role in the antioxidant and antimicrobial activities of plant extracts (Akter et al., 2016; Benabdelaziz et al., 2016; Habibatni et al., 2016; Olivier et al., 2017). Since phenolic compounds or flavonoids have variations in their structures, different compounds 
may exhibit different antioxidant and antimicrobial activities. These phenolics and flavonoids can be synthesised by plants as a defence mechanism against microbial infection (Akter et al., 2016; Habibatni et al., 2016).

There is no obvious pattern observed between the antibacterial activity and solvent polarity i.e. no increase in activity with increasing polarity of the first three solvents (hexane, chloroform and ethyl acetate) as seen earlier in the TPC, TFC and DPPH radical scavenging assays. This seems to suggest that the polarity of solvent did not play an important role in the extraction of antibacterial compounds. This could also suggest that there is no strong correlation between the antibacterial activity and antioxidant activity i.e. the high antioxidant activity did not correspond to high antibacterial activity. A similar observation was previously reported whereby the plant extracts, which had shown high antioxidant activities, showed low inhibition of bacterial growth (Borchardt et al., 2008; Koncic et al., 2010; Jang et al., 2016; Vitalini et al., 2016).

\section{CONCLUSION}

This is the first study on the antioxidant and antibacterial activities of the D. suffruticosa extracts obtained using decoction, Soxhlet extraction and solvent-solvent partitioning. In summary, the study showed that D. suffruticosa leaves had antioxidant and antibacterial activities, with the diethyl ether and ethyl acetate partition extracts being the most promising extracts. The discovery of new pharmaceutical or effective antimicrobial agents could be explored by further investigation on the bioassay-guided isolation of bioactive compounds of D. suffruticosa.

\section{ACKNOWLEDGEMENTS}

The authors wish to thank Dr Aida Mariam Basri of Universiti Teknologi Brunei for her valuable suggestions and support in this work. This work was supported by the Brunei Research Council (research grant JPKE/BRC/UBD/BRC6, 2014) and Universiti Brunei Darussalam.

\section{REFERENCES}

Addai, Z.R., Abdullah, A. \& Mutalib, S.A. 2013. Effect of extraction solvents on the phenolic content and antioxidant properties of two papaya cultivars. Journal of Medicinal Plants Research, 7: 3354-3359.

Akter, K., Barnes, E.C., Brophy, J.J., Harrington, D., Elders, Y.C., Vemulpad, S.R. \& Jamie, J.F. 2016. Phytochemical profile and antibacterial and antioxidant activities of medicinal plants used by Aboriginal people of New South Wales, Australia. Evidence-Based Complementary and Alternative Medicine, 2016: 1-14.

Alam, M.B., Chowdhury, N.S., Mazumder, M.E.H. \& Haque, M.E. 2011. Antimicrobial and toxicity study of different fractions of Dillenia indica Linn. bark extract. International Journal of Pharmaceutical Sciences and Research, 2: 860866.

Armania, N., Yazan, L.S., Musa, S.N., Ismail, I.S., Foo, J.B., Chan, K.W., Noreen, H., Hisyam, A.H., Zulfahmi, S. \& Ismail, M. 2013. Dillenia suffruticosa exhibited antioxidant and cytotoxic activity through induction of apoptosis and G2/M cell cycle arrest. Journal of Ethnopharmacology, 146: 525-535.

Asghar, N., Naqvi, S.A., Hussain, Z., Rasool, N., Khan, Z.A., Shahzad, S.A., Sherazi, T.A., Janjua, M.R., Nagra, S.A., Zia-Ul-Haq, M. \& Jaafar, H.Z. 2016. Compositional difference in antioxidant and antibacterial activity of all parts of the Carica papaya using different solvents. Chemistry Central Journal, 10(5): 1-11.

Ayoola, G.A., Coker, H.A.B., Adesegun, S.A., Adepoju-Bello, A.A., Obaweya, K., Ezennia, E.C. \& Atangbayila, T.O. 2008. Phytochemical screening and antioxidant activities of some selected medicinal plants used for malaria therapy in Southwestern Nigeria. Tropical Journal of Pharmaceutical Research, 7: 10191024.

Belyagoubi, L., Belyagoubi-Benhammou, N. \& Coustard, J.M. 2016. Effects of extraction solvents on phenolic content and antioxidant properties of Pistacia atlantica Desf fruits from Algeria. International Food Research Journal, 23: 948-953. 
Benabdelaziz, I., Marcourt, L., Benkhaled, M., Wolfender, J.-L. \& Haba, H. 2017. Antioxidant and antibacterial activities and polyphenolic constituents of Helianthemum sessiliflorum Pers. Natural Product Research, 31(6): 686-690.

Boeing, J.S., Barizão, É.O., Silva, B.C.e., Montanher, P.F., Almeida, V. de C. \& Visentainer, J.V. 2014. Evaluation of solvent effect on the extraction of phenolic compounds and antioxidant capacities from the berries: application of principal component analysis. Chemistry Central Journal, 8(1): 48-57.

Borchardt, J.R., Wyse, D.L., Sheaffer, C.C., Kauppi, K.L., Fulcher, R.G., Ehlke, N.J., Biesboer, D.D. \& Bey, R.F. 2008. Antioxidant and antimicrobial activity of seed from plants of the Mississippi river basin. Journal of Medicinal Plant Research, 2(4): 81-93.

Department of Agriculture, 2000. Medicinal Plants of Brunei Darussalam, Revised Edition, Ministry of Industry and Primary Resources, Brunei Darussalam. p.54.

Ebrahimzadeh, M.A., Pourmorad, F. \& Hafezi, S. 2008. Antioxidant activities of Iranian corn silk. Turkish Journal of Biology, 32: 43-49.

Edeoga, H.O., Okwu, D.E. \& Mbaebie, B.O. 2005. Phytochemical constituents of some Nigerian medicinal plants. African Journal of Biotechnology, 4(7): 685-688.

Goh, M.P.Y., Basri, A.M., Yasin, H., Taha, H. \& Ahmad, N. 2017. Ethnobotanical review and pharmacological properties of selected medicinal plants in Brunei Darussalam: Litsea elliptica, Dillenia suffruticosa, Dillenia excelsa, Aidia racemosa, Vitex pinnata and Senna alata. Asian Pacific Journal of Tropical Biomedicine, 7: 173-180.

Goze, I., Alim, A., Tepe, A.S., Sokmen, M., Sevgi, K. \& Tepe, B. 2009. Screening of the antioxidant activity of essential oil and various extracts of Origanum rotundifolium Boiss. from Turkey. Journal of Medicinal Plants Research, 3: $246-254$.

Graham, J.G., Quinn, M.L., Fabricant, D.S. \& Farnsworth, N.R. 2000. Plants used against cancer - An extension of the work of Jonathan Hartwell. Journal of Ethnopharmacologyl, 73: 347-377.

Habibatni, S., Miceli, N., Ginestra, G., Maameri, Z., Bisignano, C., Cacciola, F., Utczas, M., Mondello, L., Anwar, S., Benayache, S., Atrouz, D., Benayache, F. \& Taviano, M.F. 2016. Antioxidant and antibacterial activity of extract and phases from stems of Spartium junceum L. growing in Algeria. International Journal of Phytomedicine, 8: 37-46.
Hanum, F. 1999. The Use of Medicinal Plant Species by the Temuan Tribe of Ayer Hitam Forest, Selangor, Peninsular Malaysia. Pertanika Journal of Tropical Agricultural Science, 22: 85-94.

Jang, D., Lee, J., Eom, S.H., Lee, S.M., Gil, J., Lim, H. Bin. \& Hyun, T.K. 2016. Composition, antioxidant and antimicrobial activities of Eleutherococcus senticosus fruit extracts. Journal of Applied Pharmaceutical Science, 6(3): 125-130.

Karimi, E., Jaafar, H.Z. \& Ahmad, S. 2011. Phytochemical analysis and antimicrobial activities of methanolic extracts of leaf, stem and root from different varieties of Labisa pumila Benth. Molecules, 16: 4438-4450.

Kebbab-Massime, R., Labed, B. \& Boutamine-Sahki, R. 2017. Evaluation of antimicrobial and antioxidant activities of methanolic extracts of flavonoids obtained from the leaves of Solenostemma argel plant collected in the region of Tamanrasset, Algeria. Journal of Plant Biochemistry \& Physiology, 5: 1-5.

Kolar, F.R., Kamble, V.S., Dixit, G.B. \& Firdose, R.K. 2011. Phytochemical constituents and antioxidant potential of some underused fruits. African Journal of Pharmacy and Pharmacology, 5: 2067-2072.

Koncic, M.Z., Kremera, D., Gruzb, J., Strnad, M., Biševac, G., Kosalec, I., Šamec, D., PiljacZegarac, J. \& Karlovic, K. 2010. Antioxidant and antimicrobial properties of Moltkia petraea (Tratt.) Griseb. flower, leaf and stem infusions. Food and Chemical Toxicology, 48: 1537-1542.

Kuete, V., Ngameni, B., Simo, C.C.F., Tankeu, R.K., Ngadjui, B.T., Meyer, J.J.M., Lall, N. \& Kuiate, J.R. 2008. Antimicrobial activity of the crude extracts and compounds from Ficus chlamydocarpa and Ficus cordata (Moraceae). Journal of Ethnopharmacology, 120: 17-24.

Kumar, S., Kumar, V. \& Prakash, O.M. 2011. Free Radicals scavenging effect of Dillenia indica leaves. Asian Journal of Pharmaceutical and Biological Research, 1: 169-173.

Lakache, Z., Tigrine-Kordjani, Tigrine, C., Aliboudhar, H. \& Kameli, A. 2016. Phytochemical screening and antioxidant properties of methanolic extract and different fractions of Crataegus azarolus leaves and flowers from Algeria. International Food Research Journal, 23: 1576-1583.

Matić, S., Stanic, S., Mihailović, M. \& Bogojevic, D. 2016. Cotinus coggygria Scop.: An overview of its chemical constituents, pharmacological and toxicological potential. Saudi Journal of Biological Sciences, 23: 452-461. 
Olivier, M.T., Muganza, F.M., Shai, L.J., Gololo, S.S. \& Nemutavhanani, L.D. 2017. Phytochemical screening, antioxidant and antibacterial activities of ethanol extracts of Asparagus suaveolens aerial parts. South African Journal of Botany, 108: 41-46.

Rashid, M.A., Parvin, M.N., Rahman, M.S. \& Islam, M.S. 2009. Chemical and biological investigations of Dillenia indica Linn. Bangladesh Journal of Pharmacology, 4: 122125.

Senguttuvan, J., Paulsamy, S. \& Karthika, K. 2014. Phytochemical analysis and evaluation of leaf and root parts of the medicinal herb, Hypochaeris radicata $\mathrm{L}$. for in vitro antioxidant activities. Asian Pacific Journal of Tropical Biomedicine, 4: S359-67.

Sharma, A. \& Cannoo, D.S. 2016. A comparative study of effects of extraction solvents/ techniques on percentage yield, polyhenolic composition, and antioxidant potential of various extracts obtained from stems of Nepeta leucophylla: RP-HPLC-DAD assessment of its polyhenolic constituents. Journal of Food Biochemistry, 41: 1-12.

Snoussi, M., Trabelsi, N., Dehmeni, A., Benzekri, R., Bouslama, L., Hajlaoui, B., Al-sieni, A. \& Papetti, A. 2016. Phytochemical analysis, antimicrobial and antioxidant activities of Allium roseum var. odoratissimum (Desf.) Coss extracts. Industrial Crops and Products, 89: 533-542.

Sulaiman, S.F., Sajak, A.A.B., Ooi, K.L., Supriatno. \& Seow, E.M. 2011. Effect of solvents in extracting polyphenols and antioxidants of selected raw vegetables. Journal of Food Composition and Analysis, 24: 506-515.
Truong, D.H., Nguyen, D.H., Ta, N.T.A., Bui, A.V., Tuong, H.D. \& Nguyen, H.C. 2019. Evaluation of the use of different solvents for phytochemical constituents, antioxidants, and in vitro anti-inflammatory activities of Severinia buxifolia. Journal of Food Quality, 2019.

Tuama, A.A. \& Mohammed, A.A. 2019. Phytochemical screening and in vitro antibacterial and anticancer activities of the aqueous extract of Cucumis sativus. Saudi Journal of Biological Sciences, 26: 600-604.

Vats, S. 2012. Antioxidant Activity of Callus Culture of Vigna unguiculata (L.) Walp. Researcher, 4(6): 22-24.

Vélez-González, F., Ortegón-Reyna, D., RamosOrganillo, Á.A., Peraza-Campos, A.L., SumayaMartínez, M.T., Tapia-Benavides, R. \& Martínez-Martínez, F.J. 2008. Structural study and antioxidant activity determination of $(2 E)$ $N$-[2-(morpholin-4-yl)ethyl]-cinnamide. ARKIVOC, 2008: 55-64.

Vitalini, S., Madeo, M., Tava, A., Iriti, M., Vallone, L., Avato, P., Cocuzza, C.E., Simonetti, P. \& Argentieri, M.P. 2016. Chemical profile, antioxidant and antibacterial activities of Achillea moschata Wulfen, an endemic species from the Alps. Molecules, 21: 830-845.

Wiart, C., Mogana, S., Khalifah, S., Mahan, M., Ismail, S., Buckle, M., Narayana, A.K. \& Sulaiman, M. 2004. Antimicrobial screening of plants used for traditional medicine in the state of Perak, Peninsular Malaysia. Fitoterapia, 75: 68-73.

Zhang, W., Hu, J.F., Lv, W.W., Zhao, Q.C. \& Shi, G.B. 2012. Antibacterial, antifungal and cytotoxic isoquinoline alkaloids from Litsea cubeba. Molecules, 17: 12950-12960. 